\title{
SOME EXCLUSION CAGES DO NOT EXCLUDE PREDATORS
}

\author{
OLGA M. C. C. AMEIXA ${ }^{1,3^{*}}$ AND PAVEL KINDLMANN ${ }^{1,2}$ \\ ${ }^{1}$ Department of Biodiversity Research, Global Change Research Centre AS CR, Na Sádkách 7, České Budějovice, Czech Republic \\ ${ }^{2}$ Charles University, Benátská 2, Prague, Czech Republic \\ ${ }^{3}$ University of South Bohemia, České Budějovice, Czech Republic \\ ${ }^{*}$ Coresponding author: olgameixa@portugalmail.pt
}

\begin{abstract}
Exclusion techniques, such as cages, are the most frequently used means of evaluating the efficiency of natural enemies in suppressing the abundance of their prey. The growth rates and peak densities of aphid populations within cages are usually larger than those in uncaged populations. However, cages change the microenvironment and prevent aphids from emigrating. Attempts were made to avoid the change in the microenvironment by using cages with a large $(8 \mathrm{~mm})$ mesh. Here we test the hypothesis that because of the large mesh size, predators can easily penetrate into such cages during an experiment. Our results have shown that cages with a large (8 $\mathrm{mm}$ ) mesh size do not prevent predators from entering the cages and therefore cannot be used as "exclusion cages" for measuring the effect of predators on aphid numbers. Other methods of assessing the effectiveness of natural enemies in reducing the abundance of their prey, like removing the predators or direct observations, should be used instead.
\end{abstract}

Keywords: predator effectiveness, exclusion cages, ladybirds, aphids

\section{Introduction}

Exclusion techniques, such as cages, are the most frequently used means of evaluating the efficiency of natural enemies in suppressing the abundance of their prey (Luck et al. 1988; Kindlmann and Dixon 2010). The growth rates and peak densities of aphid populations within cages are usually larger than those in uncaged populations (e.g., Chambers et al. 1983; Elliott and Kieckhefer 2000; Michels et al. 2001; Basky 2003; Cardinale et al. 2003; Schmidt et al. 2003). However, cages change the microenvironment (Hand and Keaster 1967), especially temperature, which is thought to be important in determining the outcome of predator-prey interactions (Frazer and Gilbert 1976; Frazer et al. 1981).

Cages prevent aphids from emigrating, which is their usual response to high density (Dixon 1998, 2005; Kindlmann and Dixon 2010). Gardiner et al. (2009) show that after 14 days of caging there are an average of $20.7 \pm 1.4$ alates per plant within exclusion cages but only $1.8 \pm 0.1$ alates per plant in un-caged plots. Interestingly, when only polythene enclosures, $60 \mathrm{~cm}$ high, buried to a depth of $30 \mathrm{~cm}$, and not cages, were used, which do not affect the microenvironment of the manipulated plots, allow aphids to emigrate, but exclude ground predators, there was no difference in the number of grain aphids in control plots and those where the number of ground predators were reduced (Holland et al. 1996).

Attempts to avoid the change in the microenvironment by using cages with a large $(8 \mathrm{~mm})$ mesh size (Schmidt et al. 2003) do not reduce predator densities within cages (Kindlmann and Dixon 2010). The ques- tion arises, whether this is because some inconspicuous predator stages tend to be overlooked when setting up the cages, or whether predators penetrate into such cages during the experiment. We hypothesize that the latter is the case and test this using a small version of cages used by Schmidt et al. (2003).

\section{Material and methods}

The aphid (Acyrthosiphon pisum), was obtained from stock cultures, which were reared on broad beans, in controlled conditions, at $25 \pm 1{ }^{\circ} \mathrm{C}$ and a $16 \mathrm{~L}: 8 \mathrm{D}$ photoperiod. Individuals of different aphidophagous coccinellid species were collected in the field (Table 1).

Table 1 Species released outside the cage.

\begin{tabular}{|l|c|c|}
\hline \multicolumn{1}{|c|}{ Species } & Number & Size (mm) \\
\hline Adalia bipunctata & 15 & $3.5-5.5$ \\
\hline Harmonia axyridis & 8 & $7-8$ \\
\hline Calvia quattuordecimguttata & 1 & $4.5-6$ \\
\hline Adonia variegata & 1 & $3-5.5$ \\
\hline
\end{tabular}

The experiment was performed in a climatic chamber $\left(25 \pm 1{ }^{\circ} \mathrm{C}\right.$ and $16 \mathrm{~L}: 8 \mathrm{D}$ photoperiod). A tray was prepared with five pots each containing four bean plants, with a pot in each corner and one in the centre, the space between the pots was filled with soil (Fig. 1). The plants in the centre pot were each infested with 20 aphids. The centre pot was protected from predators by a cage, $20 \mathrm{~cm}$ in diameter and $50 \mathrm{~cm}$ in height, covered with $8 \mathrm{~mm}$ mesh sprayed with entomological glue. 


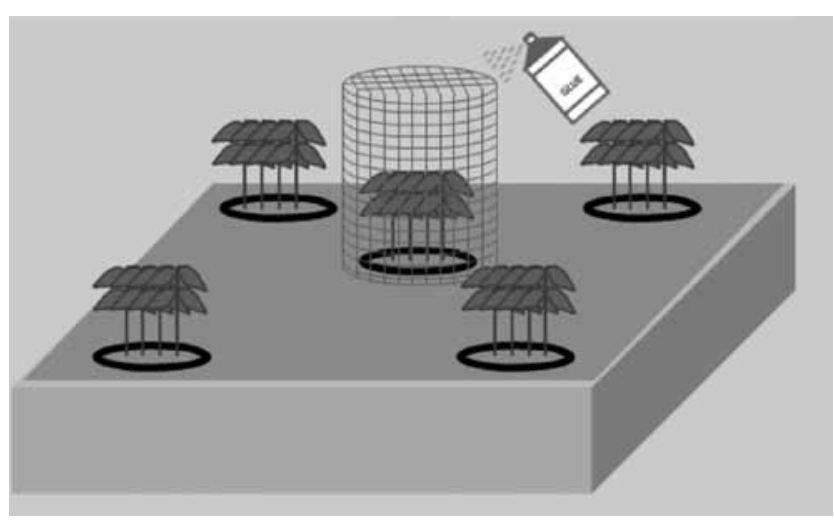

Fig. 1 Experimental setup.

The coccinellids were released in the climatic chamber outside the centre cage and observations recorded at $0.5 \mathrm{~h}$ and $24 \mathrm{~h}$ after their release to determine if the predators entered the centre cage.

\section{Results}

The observations are summarized in Table 2. Only 1 of 25 ladybirds became entangled in the glue sprayed on the mesh enclosing the centre cage. After 24 hours almost one half (12 out of 25) of the ladybirds had entered the centre cage - so the glue did not prevent them from entering. During the observations several individuals were seen entering then leaving and re-entering the cage, but the frequency with which this occurred was not recorded. Proportionally more small than large individuals were recorded in the cage after 24 hours (Fig. 2). However, even the largest individuals were able to enter the cage (Fig. 2).

Table 2 Summary of the observations recorded 0, 0.5 and 24 hours after the start of the experiment.

\begin{tabular}{|c|c|}
\hline Time (h) & \multicolumn{1}{|c|}{ Observations } \\
\hline 0 & - Predators released \\
\hline 0.5 & - Adonia variegata inside the cage \\
\hline 24 & Inside the cage: \\
& -9 out of 15 Adalia bipunctata \\
& -2 out of 8 Harmonia axyridis \\
& -1 out of 1 Calvia quattuordecimguttata \\
& Outside the cage: \\
& -5 out of 15 Adalia bipunctata \\
& -6 out of 8 Harmonia axyridis \\
& -1 out of 1 Adonia variegata \\
& Stuck to the cage: \\
& -1 out of 15 Adalia bipunctata \\
\end{tabular}

\section{Discussion}

Our results have shown that cages with a large $(8 \mathrm{~mm})$ mesh size, as used by Schmidt et al. (2003), do not prevent predators from entering the cages and therefore cannot be used as "exclusion cages" for measuring the

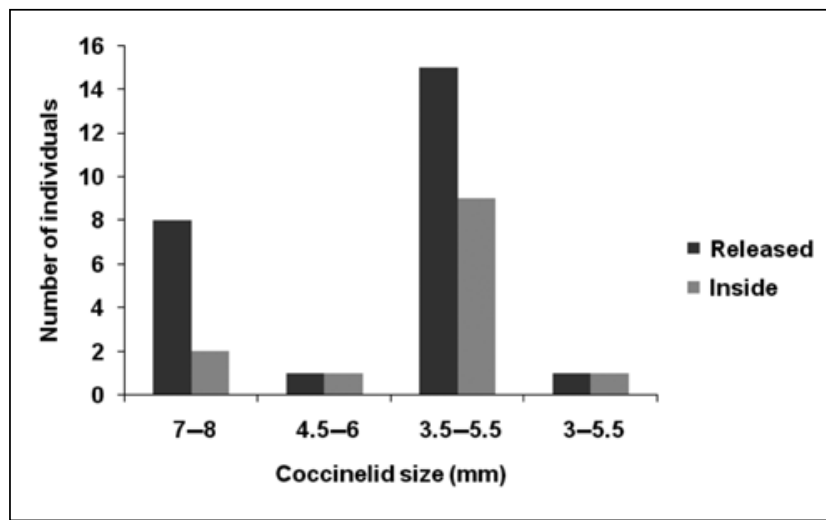

Fig. 2 Numbers of coccinellids of different sizes released outside the centre cage and the numbers of the different size classes that entered the cage.

effect of predators on aphid numbers. Other methods of assessing the effectiveness of natural enemies in reducing the abundance of their prey, like removing the predators (Kindlmann et al. 2005) or direct observations like those in Costamagna and Landis (2007), should be used instead.

\section{REFERENCES}

Basky Z (2003) Predators and parasitoids on different cereal aphid species under caged and no caged conditions in Hungary. Pp 95-102 in AO Soares, MA Ventura, V Garcia and J-L Hemptinne (eds). Proceedings of the 8th International Symposium on Ecology of Aphidophaga: Biology, Ecology and Behaviour of Aphidophagous Insects. Arquipélago - Life and Marine Science, Supplement 5, Ponta Delgada, Azores, Portugal.

Cardinale BJ, Harvey CT, Gross K, Ives AR (2003) Biodiversity and biocontrol: emergent impacts of a multi-enemy assemblage on pest suppression and crop yield in an agroecosystems. Ecol Letters 6: 857-865.

Chambers RJ, Wellings PW, Dixon AFG (1985) Sycamore aphid numbers and population density 11 . Some processes. J Anim Ecol 54: 425-442.

Costamagna AC, Landis DA (2007) Quantifying predation on soybean aphid through direct field observations. Biol Control 42: $16-24$.

Dixon AFG (2005) Insect Herbivore-Host Dynamics: ShrubDwelling Aphids. Cambridge University Press, Cambridge.

Dixon AFG (1998) Aphid Ecology: An Optimization Approach, 2nd ed. Chapman and Hall, London.

Elliott NC, Kieckhefer RW 2000. Response by coccinellids to spatial variation in cereal aphid density. Popul Ecol 42: 81-90.

Frazer BD, Gilbert N (1976) Coccinellids and aphids: a quantitative study of the impact of adult ladybirds (Coleoptera: Coccinellidae) preying on field populations of pea aphids (Homoptera: Aphididae). J Ent Soc BC 73: 33-56.

Frazer BD, Gilbert N, Ives PM, Raworth DA (1981) Predator reproduction and the overall predator-prey relationship. Can Ent 113: 1015-24.

Gardiner M M, Landis DA, Gratto C, Difonzo CD, O’Neal M, Chacon JM, Wayo MT, Schmidt NP, Mueller EE, Heimpel GE (2009) Landscape diversity enhances biological control of an introduced crop pest in the north-central USA. Ecol Appl 19: $143-154$ 
Hand LF, Keaster AJ (1967) The environment of an insect field cage. J Econ Ent 60: 910-15.

Kindlmann P, Dixon AFG (2010) Modelling population dynamics of aphids and their natural enemies. Pp 1-20 in P Kindlmann, AFG Dixon and JP Michaud (eds). Aphid Biodiversity under Environmental Change: Patterns and Processes. Springer, Dordrecht.

Kindlmann P, Yasuda H, Kajita Y, Dixon AFG (2005) Field test of the effectiveness of ladybirds in controlling aphids. Pp 441-447 in MS Hoddle (ed). International Symposium on Biological Control of Arthropods, September 12-16, 2005, Davos, Switzerland. USDA Forest Service, FHTET-2005-08.
Luck RF, Shepard BM, Kenmore PE (1988) Experimental methods for evaluating arthropod natural enemies. Ann Rev Ent 33: 367-91.

Michels GJ, Elliott NC, Romero RA, Owings DA, Bible JB (2001) Impact of indigenous coccinellids on Russian wheat aphids and greenbugs (Homoptera: Aphididae) infesting winter wheat in the Texas Panhandle. Southw Entomologist 26: 97-114.

Schmidt MH, Lauer A, Purtauf T, Thies C, Schaefer M, Tscharntke T (2003) Relative importance of predators and parasitoids for cereal aphid control. Proc Roy Soc London B 270: 1905-1909. 